\title{
Cyatheaceae endémicas del Perú
}

\section{Blanca León ${ }^{1,2}$}

${ }^{1}$ Museo de Historia Natural, Av. Arenales 1256, Aptdo. 14-0434, Lima 14, Perú

2 Plant Resources Center, University of Texas at Austin, Austin TX 78712 EE.UU.

blanca.leon@mail.utexas.edu

\section{Resumen}

Esta es una de las familias que incluye mayormente helechos arborescentes. En el Perú, esta familia está representada por cuatro géneros y más de 60 especies (Tryon \& Stolze 1989a, Smith et al., 2005). Siete especies en dos géneros son consideradas endemismos peruanos, estando escasamente representadas en los herbarios. La mayoría de estos endemismos se encuentra en los bosques de las regiones del Bosque Húmedo Montano y Premontano en el centro y sur del país, entre los 850 y $3300 \mathrm{~m}$ de altitud, generalmente asociados a localidades escasamente herborizadas. Cuatro de esas especies se conocen de áreas protegidas.

Palabras clave: Cyatheaceae, Perú, endemismo.

\section{Abstract}

The Cyatheaceae is one of the fern families that mainly include tree-ferns. In Peru, this family is represented by four genera and over 60 species (Tryon \& Stolze, 1993; Smith et al., 2005). Seven species in two genera are considered to be Peruvian endemics, being scarcely represented in plant collections. The majority of these endemic taxa are found in forests of the Humid Montane and Premontane Forests regions, in the central and southern part of the country, between 850 and 3300 m elevation, generally associated with localities scarcely botanized. Four species are represented in a protected area.

Key words: Cyatheaceae, Peru, endemism.

\section{Cnemidaria alatissima Stolze}

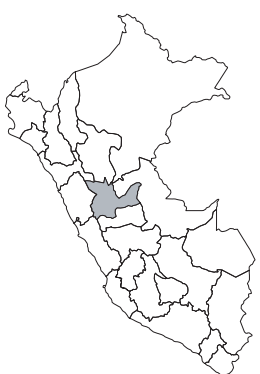

\section{CR, B1ab(iii)}

Publicación: Fieldiana Bot. 37: 55. 1974

Colección tipo: T.R. Dudley 13282

Herbarios: GH, NA, US.

Nombre común: Desconocido,

Registro departamental: HU.

Regiones Ecológicas: BMHM; $1540 \mathrm{~m}$. SINANPE: RCS

Herbarios peruanos: Ninguno.

Observaciones: Este helecho se conoce solamente de una localidad, en la cuenca del Llulla Pichis, un afluente del Pachitea, reconocida hoy en la Reserva Comunal del Sira. No ha vuelto a ser recolectada desde 1969. Esta especie es aparentemente dependiente de cobertura boscosa, la cual, para su rango altitudina, está sujeta a la tala y deforestación. Otras localidades vecinas en las estribaciones andinas orientales, en el centro del país podrían incluir poblaciones de esta especie; sin embargo, no ha sido registrada en la zona del Huallaga, vecina a Tingo María.

\section{Cyathea multisegmenta R.M. Tryon}

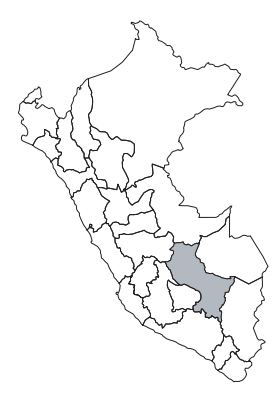

\section{EN, B1ab(iii)}

Publicación: Contr. Gray Herb. 206: 65. 1976.

Colección tipo: T.R. Dudley 11326

Herbarios: GH, NA, US.

Nombre común: Desconocido.

Registro departamental: CU.

Regiones Ecológicas: BMHM; 1730_ $2100 \mathrm{~m}$.

SINANPE: PNM

Herbarios peruanos: CUZ (1), USM (1).
Observaciones: Este helecho arborescente fue recolectado por primera vez en 1968, de la Cordillera de Vilcabamba; una colección adicional, realizada en 2003, ha permitido confirmar a esta especie y ampliar su área de presencia en aproximadamente $150 \mathrm{~km}^{2}$. Esta especie es, al parecer, rara en las localidades conocidas. Una sola población se halla en un área protegida, el Parque Nacional Manu; sin embargo poco se sabe del estatus de otros ambientes propicios para esta especie fuera de áreas no protegidas.

\section{Cyathea rufescens (Mett. ex Kuhn) Domin}

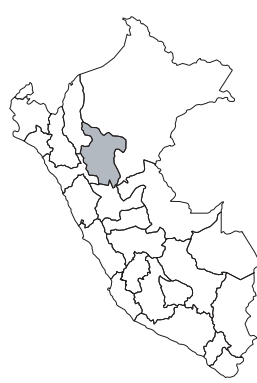

$$
\text { EN, B1a+2a }
$$

Publicación: Pteridophyta 264. 1929.

Colección tipo: R. Spruce 4727

Herbarios: B, K, NY.

Nombre común: Desconocido.

Registro departamental: SM.

Regiones Ecológicas: BMHP; 850—1200 $\mathrm{m}$.

SINANPE: Sin registro.

Herbarios peruanos: USM (1).

Observaciones: Esta especie de helecho arborescente fue reconocida en Sphaeropteris por Tryon \& Stolze (1989). Además del tipo, recolectado a mediados del siglo XIX, en la cuenca del Mayo, está representada por una colección realizada 150 años después, en las cercanías de la localidad original. Si bien en esa zona quedan remanentes de vegetación que podrían incluir individuos de esta especie, ésta se encuentra severamente afectada por la tala y deforestación. 


\section{Cyathea ruiziana Klotzsch}

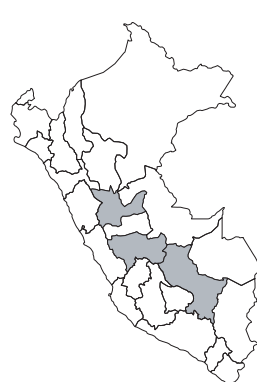

EN, B1a+2a

Publicación: Linnaea 20: 439. 1847.

Colección tipo: H. Ruiz 72

Herbarios: B, US.

Nombre común: Desconocido.

Registro departamental: CU, HU, JU.

Regiones Ecológicas: BMHM; 2050-

$3320 \mathrm{~m}$

SINANPE: PNM

Herbarios peruanos: USM (3).

Observaciones: Este helecho arborescente se conoce del centrosur del Perú, con un área de presencia de $750 \mathrm{~km}^{2}$. Localmente parece ser ocasional en su ocurrencia. Al igual que otras especies en el género, está asociada a ambientes boscosos. Ha sido registrado en el Parque Nacional Manu, población que representa la distribución más meridional que se conoce.

\section{Cyathea vilhelmii Domin}

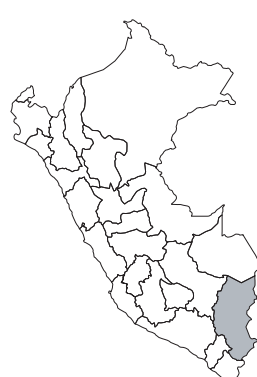

\section{CR, B1ab(iii)}

Publicación: Pteridophyta 264. 1929.

Colección tipo: W. Lechler 2654

Herbarios: B, GH.

Nombre común: Desconocido.

Registro departamental: PU.

Regiones Ecológicas: BMHM; $2177 \mathrm{~m}$.

SINANPE: Sin registro.

Herbarios peruanos: Ninguno.

Observaciones: Helecho arborescente conocido sólo de una localidad, Tatanara, en el sur del país, en la cuenca del San Gabán. Los dos únicos ejemplares que representan a esta especie fueron recolectadas en el siglo XIX. La cuenca original está sujeta a fuerte deforestación y puede inferirse que afecte las poblaciones de esta especie. La localidad tipo ha sido escasamente herborizada y esto pueda contribuir a lo poco que se la conoce.

\section{Trichipteris flava R.M. Tryon}

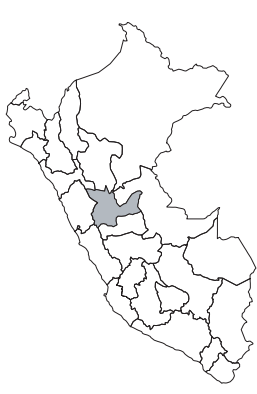

DD

Publicación: Fieldiana Bot., n.s. 20: 125. 1989.

Colección tipo: D. Soejarto 1432

Herbarios: GH.

Nombre común: Desconocido.

Registro departamental: HU.

Regiones Ecológicas: BMHM; 2500 m.

SINANPE: Sin registro.

Herbarios peruanos: Ninguno.

Observaciones: Helecho arborescente conocido sólo del ejemplar tipo, el cual proviene de una zona de alta deforestación, debido a la expansión rural y agrícola. El estatus taxonómico de esta entidad es incierto (M. Lehnert, com. pers.).

\section{Trichipteris serpens R.M. Tryon}

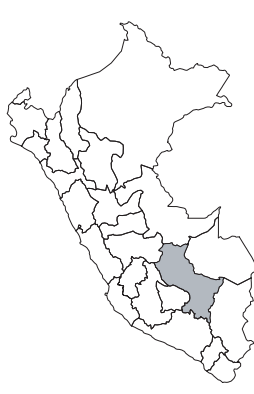

\section{DD}

Publicación: Fieldiana Bot., n.s. 20: 126. 1989.

Colección tipo: T.R. Dudley 10949

Herbarios: GH, NA.

Nombre común: Desconocido.

Registro departamental: CU.

Regiones Ecológicas: BMHM; $2900 \mathrm{~m}$. SINANPE: PNO

Herbarios peruanos: Ninguno.

Observaciones: Este helecho arborescente se conoce solamente de una localidad. Descrita sobre la base de un ejemplar estéril, se requiere una evaluación taxonómica sobre la identidad de esta especie, que de ser aceptada debería serlo en el género Cyathea. 